\title{
Mutation of Critical GIRK Subunit Residues Disrupts N- and C-Termini Association and Channel Function
}

\author{
Radmila Sarac, Ping Hou, Karen M. Hurley, David Hriciste, Noam A. Cohen, and Deborah J. Nelson \\ Department of Neurobiology, Pharmacology, and Physiology, The University of Chicago, Chicago, Illinois 60637
}

\begin{abstract}
The subfamily of G-protein-linked inwardly rectifying potassium channels (GIRKs) is coupled to G-protein receptors throughout the CNS and in the heart. We used mutational analysis to address the role of a specific hydrophobic region of the GIRK1 subunit. Deletion of the GIRK1 C-terminal residues 330-384, as well as the point mutation I331R, resulted in a decrease in channel function when coexpressed with GIRK4 in oocytes and in COS-7 cells. Surface protein expression of GIRK1 I331R coexpressed with GIRK4 was comparable with wild type, indicating that subunits assemble and are correctly localized to the membrane. Subsequent mutation of homologous residues in both the GIRK4 subunit and Kir2.1 ( $\mathrm{G}_{\beta \gamma}$-independent inward rectifier) also resulted in a decrease in channel function. Intracellular domain associations resulted in the coimmunoprecipitation of the GIRK1 N and C termini and GIRK4 N and C termini. The point mutation I331R in the GIRK1 C terminus or L337R in the GIRK4 C terminus decreased the association between the N and C termini. Mutation of a GIRK1 N-terminal hydrophobic residue, predicted structurally to interact with the C-terminal domain, also resulted in a decrease in channel function and termini association. We hypothesize that the hydrophobic nature of this GIRK1 subunit region is critical for interaction between adjacent termini and is permissive for channel gating. In addition, the homologous mutation in cytoplasmic domains of Kir2.1 (L330R) did not disrupt association, suggesting that the overall structural integrity of this region is critical for inward rectifier function.
\end{abstract}

Key words: potassium; [K]; channel; carbachol; structure; voltage clamp; rectification

\section{Introduction}

G-protein-linked inwardly rectifying potassium channels (GIRKs) mediate important physiological functions in the heart and affect excitability in various neuronal populations (Dascal et al., 1993; Kofuji et al., 1995; Krapivinsky et al., 1995b; Lesage et al., 1995). Thus far, the family consists of four mammaliancloned members GIRK1-GIRK4 (or Kir3.1-Kir3.4) (Kubo et al., 1993a; Lesage et al., 1994; Krapivinsky et al., 1995b; Dascal, 1997; Jan and Jan, 1997). In cardiac tissue, the GIRK conductance is attributable to activation of hetero-oligomeric channels composed of GIRK1 (G1) and GIRK4 (G4), although homomeric GIRK4 channels may also be functionally significant (Krapivinsky et al., 1995b; Corey and Clapham, 1998). In the CNS, various combinations of subunits are thought to comprise channels found in several brain regions (Kobayashi et al., 1995; Karschin et al., 1996; Wischmeyer et al., 1997; Inanobe et al., 1999; Jelacic et al., 2000; Leaney, 2003). The mechanisms determining GIRK subunit assembly have only been broadly addressed. The GIRK subunit core regions and intracellular C termini (CT) appear to be important in subunit multimerization as well as recognition.

Received Jan. 29, 2004; revised Jan. 4, 2005; accepted Jan. 5, 2005.

This work is supported by National Institute of Neurological Disorders and Stroke National Research Service Award F31-NS42481 (R.S.) and Grant R01 GM36823 (D.J.N.). We thank Ping Huang and Nicole C. Robinson for helpful discussion and critical reading of this manuscript.

Correspondence should be addressed to Deborah J. Nelson, Department of Neurobiology, Pharmacology, and Physiology, The University of Chicago, Chicago, IL 60637. E-mail: nelson@uchicago.edu.

D0I:10.1523/JNEUROSCI.4783-04.2005

Copyright $\odot 2005$ Society for Neuroscience $\quad 0270-6474 / 05 / 251836-11 \$ 15.00 / 0$
Within the GIRK subunit intracellular domains, several motifs have been identified that specify cellular trafficking (Tucker et al., 1996; Woodward et al., 1997; Kennedy et al., 1999; Ma et al., 2002; Mirshahi and Logothetis, 2004).

GIRK channels are coupled to a wide range of G-proteincoupled receptor (GPCR) systems, including muscarinic, opiate, dopaminergic, adenosine, and serotonin (for review see, Dascal, 1997). After GPCR activation, direct binding of $\mathrm{G}_{\beta \gamma}$ subunits to the channel results in activation (Logothetis et al., 1987; Reuveny et al., 1994). Extensive efforts have been made to determine the precise binding site for $\mathrm{G}_{\beta \gamma}$ (Logothetis et al., 1987; Huang et al., 1995, 1997; Inanobe et al., 1995; Krapivinsky et al., 1995a, 1998; He et al., 1999, 2002; Ivanina et al., 2003; Finley et al., 2004). A consensus identifying the exact $\mathrm{G}_{\beta \gamma}$ binding domain has not been determined but is thought to comprise contributions from both the intracellular $\mathrm{N}$ termini (NT) and $\mathrm{C}$ termini (Huang et al., 1997). Studies of $G_{\beta \gamma}$ binding to GIRK1 and GIRK2 glutathione $S$-transferase (GST) fusion proteins demonstrated that not all $\mathrm{G}_{\beta \gamma}$ binding sites were identical between the two subunits (Ivanina et al., 2003). In addition to $\mathrm{G}_{\beta \gamma}$ binding, membrane phospholipids, such as phosphatidylinositol 4,5-bisphosphate, and $\mathrm{Na}^{+}$are thought to participate in GIRK channel activation (Sui et al., 1998; Ho and Murrell-Lagnado, 1999).

In this study, we examined specific GIRK1 subunit characteristics. Based on GIRK1 regions identified by previous studies as important sites in $\mathrm{G}_{\beta \gamma}$ binding and subunit interaction, we investigated a specific region of the GIRK1 C terminus, which after 
deletion or point mutation, prevents functional channel expression when coexpressed with wild-type GIRK4. Recent crystallographic structural analysis of the GIRK1 intracellular domains also indicates that this region of the GIRK1 C terminus may contact adjacent termini and be important in subunit interaction (Nishida and MacKinnon, 2002). The KirBac1.1 potassium channel crystal structure also depicts an interacting region between the intracellular termini (Kuo et al., 2003). In this study, we identified GIRK1 residues that contribute to association and channel function that may be generally important in the translation of the gating mechanism.

\section{Materials and Methods}

Molecular biology. GIRK1 was cloned from a rat insulinoma tumor cell [RIN library and a predicted amino acid sequence identical to the cardiac clone originally described (Kubo et al., 1993b)]; GIRK4 and GIRK5 were generous gifts from Dr. D. E. Clapham (Children's Hospital, Boston, MA), and Kir2.1 was a generous gift from Dr. J. Kyle (The University of Chicago, IL). The $\mathrm{m} 2$ muscarinic receptor $\left(\mathrm{m}_{2} \mathrm{R}\right)$ (Clontech, Palo Alto, $\mathrm{CA})$ in the pGEM2Z vector was subcloned into the pcDNA3.1Zeo ${ }^{+}$ vector (Invitrogen, San Diego, CA). A chimera of GIRK1 was prepared by PCR gene fusion technique in which the 32 amino acid C-peptide region of human proinsulin was transplanted to the $3^{\prime}$ end of the GIRK1 clone (Philipson et al., 1995), to produce an epitope-tagged channel. All GIRK constructs were subcloned into either the pMXT vector, obtained from Dr. P. Kofuji (University of Minnesota, Minneapolis, MN), for oocyte expression or the pEGFPN3 vector (Clontech) for mammalian cell expression, both with and without GFP (green fluorescent protein) fused to the GIRK1 or GIRK4 C terminus. Kir2.1 was subcloned into the pcDNA3.1Zeo $^{+}$vector (Invitrogen) for mammalian expression. All point mutations for both the oocytes and mammalian constructs were introduced by site-directed mutagenesis (QuikChange; Stratagene, La Jolla, CA). The FLAG epitope was introduced into the GIRK1 subunit between residues 114 and 115 as described previously (Kennedy et al., 1999) using specific primers to introduce the epitope (DYKDDDDK) and also to remove the glycosylation site N119D. The GIRK1 $330-384$ construct was made by introducing silent restriction sites that were subsequently digested, dephosphorylated, and ligated. All point-mutant GIRK1-FLAG constructs were made by site-directed mutagenesis (QuikChange; Stratagene) of the GIRK1-FLAG construct. The N terminus of GIRK1 (residues 1-83) fused with a C-terminal myc tag (EQKLISEEDL), the $\mathrm{N}$ terminus of Kir2.1 (residues 1-84) fused with a C-terminal myc tag, the $\mathrm{N}$ terminus of GIRK4 (residues 1-89) fused with a C-terminal FLAG tag, and the C terminus of GIRK4 (residues 189419) fused with a C-terminal hemagglutinin (HA) tag (YPYDVPDYA) were individually subcloned into the pcDNA3.1Zeo ${ }^{+}$vector. The GIRK1 $\mathrm{C}$ terminus [transmembrane 2 (TM2) plus $\mathrm{C}$ terminus, residues 158501], the GIRK1 C terminus $\Delta 330-384$, and the Kir2.1 C terminus (TM2 plus $C$ terminus, residues 157-427) were subcloned into a pEYFP (enhanced yellow fluorescent protein) vector (Clontech) generously provided by Dr. G. Thinakaran (The University of Chicago, Chicago, IL) containing a secretion signal, followed by YFP. cDNAs encoding the indicated C termini of Kir2.1 (residues 182-427) and GIRK1 (residues 183-501 plus C-peptide) were generated by PCR and cloned in-frame to the GST coding sequence in pGEX-4T (Amersham Biosciences, Arlington Heights, IL). $\beta$ ARK ( $\beta$-adrenergic receptor kinase) was generously provided by Dr. R. J. Lefkowitz (Duke University, Durham, NC). All point mutants were made by site-directed mutagenesis (QuikChange; Stratagene) of the respective constructs. Integrated DNA Technologies (Coralville, IA) synthesized all primers, and all constructs were sequenced at the University of Chicago Cancer Research Sequencing facility.

For oocyte experiments, the m2R construct was linearized with HindIII, and cRNA was transcribed using the T7 polymerase mMessage mMachine kit (Ambion, Austin, TX). All GIRK constructs were linearized with SalI, and cRNA was transcribed using T3 polymerase mMessage mMachine kit (Ambion). The cRNA concentration was quantified by UV absorption at $260 \mathrm{~nm}\left(A_{260}\right)$, and the quality of RNA was examined by agarose gels.

COS-7 cell culture and cDNA transfection. COS-7 cells (American Type Culture Collection, Manassas, VA) were plated in $35 \mathrm{~mm}$ dishes, $25 \mathrm{~mm}$ coverslips, or $100 \mathrm{~mm}$ dishes and grown in DMEM supplemented with $10 \%$ fetal bovine serum, $100 \mathrm{U} / \mathrm{ml}$ penicillin, and $100 \mu \mathrm{g} / \mathrm{ml}$ streptomycin. One day after plating, cells were transfected using Lipofectamine Plus (Invitrogen) with $0.5 \mu \mathrm{g}$ of m2R cDNA and $1 \mu \mathrm{g}$ of cDNA for each GIRK subunit used in electrophysiological and immunostaining experiments, and twice the amount of cDNA for protein expression experiments. In electrophysiological experiments in which EGFP-tagged subunits were not used, pEGFP vector cDNA was cotransfected at a 1:10 ratio for positive identification of transfected cells. For Kir2.1 experiments, $1 \mu \mathrm{g}$ of wild-type or Kir2.1 L330R cDNA was coexpressed with 100 ng of pEGFP vector cDNA for positive identification of transfected cells. For coimmunoprecipitation experiments, cells were transfected with $2 \mu \mathrm{g}$ of cDNA of each GIRK construct as indicated.

Electrophysiological recording from oocytes. Oocytes were removed from Xenopus laevis as described previously (Yoshii and Kurihara, 1989) and maintained at $18^{\circ} \mathrm{C}$ in OR-2 $2^{+}$solution that was changed once daily. Oocytes were injected with $50 \mathrm{nl}$ containing equal amounts of each single subunit cRNA $(\sim 5 \mathrm{ng})$ and $\mathrm{m} 2$ receptor $(\sim 2.5 \mathrm{ng})$. The OR- $2^{+}$solution contained $90 \mathrm{~mm} \mathrm{NaCl}, 1 \mathrm{~mm} \mathrm{MgCl}_{2}, 1 \mathrm{mM} \mathrm{CaCl}_{2}, 2.5 \mathrm{~mm} \mathrm{KCl}$, and $5 \mathrm{mM}$ HEPES, supplemented with $100 \mu \mathrm{g} / \mathrm{ml}$ gentamycin and $5 \mathrm{~mm}$ pyruvate, $\mathrm{pH}$ 7.6. Two-microelectrode voltage-clamp recordings were performed 2-3 d after injection at room temperature (RT) using a TURBO TEC-10C amplifier (NPI Electronics, Tamm, Germany), an ITC-16 interface (InstruTech, Great Neck, NY), and an IBM-compatible personal computer. Microelectrodes were filled with $3 \mathrm{M} \mathrm{KCl}$ and had resistances of $0.5-2$ $\mathrm{M} \Omega$. Oocytes were continuously superfused with a bath solution of 90 mм $\mathrm{NaCl}$ or $\mathrm{KCl}, 1 \mathrm{~mm} \mathrm{MgCl}_{2}$, and 5 mм HEPES, pH 7.6, with $\mathrm{NaOH} /$ $\mathrm{KOH}$. G-protein-dependent currents were induced with the addition of 5 $\mu \mathrm{M}$ carbachol (Carb) (Sigma, St. Louis, MO) to the bath solution. In all experiments, the holding potential was $-80 \mathrm{mV}$; test potentials were delivered once every second and stepped between -150 and $60 \mathrm{mV}$ in 30 $\mathrm{mV}$ intervals. Data collection and analysis were performed using Pulse/ Pulse Fit (Heka, Lambrecht, Germany), and data were plotted using the integrated graphics package IGOR (WaveMetrics, Lake Oswego, OR) or Microsoft (Seattle, WA) Excel. Data are presented as mean \pm SEM and are taken from one or several batches of oocytes. Significance of results was performed by the Kruskal-Wallis one-way ANOVA method and Dunn's test. All experiments were conducted at room temperature.

Electrophysiological recording from COS-7 cells. Whole-cell recordings were performed at room temperature $48-72 \mathrm{~h}$ after transfection in an initial bath solution consisting of the following (in mM): $140 \mathrm{NaCl}, 5.4$ $\mathrm{KCl}, 2 \mathrm{CaCl}_{2}, 1 \mathrm{MgCl}_{2}$, and 10 HEPES, $\mathrm{pH}$ 7.4. After currents in low- $\mathrm{K}^{+}$ solutions were recorded, cells were superfused with a high- $\mathrm{K}^{+}(\mathrm{HK})$ solution containing the following (in $\mathrm{mM}$ ): $5.4 \mathrm{NaCl}, 140 \mathrm{KCl}, 2 \mathrm{CaCl}_{2}, 1$ $\mathrm{MgCl}_{2}$, and $10 \mathrm{HEPES}, \mathrm{pH}$ 7.4. The pipette recording solution contained the following (in mM): $120 \mathrm{KCl}, 2 \mathrm{CaCl}_{2}, 1 \mathrm{MgCl}_{2}, 11 \mathrm{EGTA}, 33 \mathrm{KOH}, 10$ HEPES, $1 \mathrm{NaGTP}$, and $2 \mathrm{MgATP}, \mathrm{pH}$ 7.2. In some experiments, $\mathrm{CaCl}_{2}$ and EGTA were replaced with $10 \mathrm{~mm}$ BAPTA-potassium salt in the pipette, and $\mathrm{CaCl}_{2}$ was removed from the extracellular solutions with no difference in function. G-protein-dependent currents were induced with the addition of $10 \mu \mathrm{M}$ carbachol (Sigma) to the bath solution. $\mathrm{K}^{+}$currents were blocked with $500 \mu \mathrm{M} \mathrm{BaCl}$ added to the high- $\mathrm{K}^{+} /$carbachol solution. In all experiments, the holding potential was $-80 \mathrm{mV}$; test potentials were delivered in steps between -160 and $50 \mathrm{mV}$ in $30 \mathrm{mV}$ intervals. Whole-cell currents were recorded with an EPC-9 (InstruTech) patch-clamp amplifier at $2 \mathrm{kHz}$ and low-pass filtered at $1 \mathrm{kHz}$. Stimulation and data acquisition were controlled by the PULSE software package, and data analysis was performed with IGOR software (Wave Metrics). Data are presented as means \pm SEM. Significance of results was determined using Student's $t$ test. 
Protein expression/Western blotting. COS-7 cells were grown in 100 $\mathrm{mm}$ dishes and transfected with $2 \mu \mathrm{g}$ of each subunit as indicated with Lipofectamine Plus (Invitrogen). Cells were washed and lysed with buffer containing 50 mu Tris, pH 7.4, 150 mм NaCl, 1\% NP-40, 1 mм EDTA, 1 $\mathrm{mM}$ PMSF, and $1 \mu \mathrm{g} / \mathrm{ml}$ each aprotinin, leupeptin, and pepstatin for 45 $\min$ at $4^{\circ} \mathrm{C}, 48 \mathrm{~h}$ after transfection. Cells were centrifuged at $14,000 \times g$ for $20 \mathrm{~min}$ at $4^{\circ} \mathrm{C}$. Supernatant was removed and measured for protein concentration (BCA reagent; Pierce, Rockford, IL), and samples were solubilized with sample buffer containing $10 \mathrm{~mm}$ DTT and boiled for 5 min. Samples were resolved by SDS-PAGE, subsequently transferred to polyvinylidene difluoride membrane, and blocked with 5\% milk for 30 min at room temperature. Blots were probed with rat $\alpha$-C-peptide at 1:100 (generously provided by Dr. L. Philipson, The University of Chicago, Chicago, IL), followed by goat HRP- $\alpha$-rat (KPL, Gaithersburg, MD) or $\alpha$-GIRK1 (Alomone Labs, Jerusalem, Israel) at 1:500, followed by goat HRP $\alpha$-rabbit (Amersham Biosciences).

GST fusion proteins and $\beta \gamma$ binding assay. GST fusion protein constructs (described above in Molecular biology) were transformed into BL21, grown to an $\mathrm{OD}_{600}$ of 0.6, induced with $1 \mathrm{~mm} \mathrm{IPTG,} \mathrm{and} \mathrm{grown} \mathrm{for}$ $3 \mathrm{~h}$. Bacteria were pelleted and resuspended in $13 \mathrm{ml}$ of lysis buffer [50 mм Tris- $\mathrm{HCl}, \mathrm{pH} 8.2,150 \mathrm{~mm} \mathrm{NaCl}, 2$ mM EDTA, and protease inhibitors ( $1 \mathrm{~mm}$ PMSF, $2 \mathrm{mg} / \mathrm{l}$ chymostatin, $2 \mathrm{mg} / \mathrm{l}$ pepstatin, $2 \mathrm{mg} / \mathrm{l}$ antipain, and $4 \mathrm{mg} / \mathrm{l}$ leupeptin)]. Suspension was sonicated four times for $15 \mathrm{~s}$. Triton X-100 was added to a final concentration of $1 \%$. Suspension was rotated at RT for $15 \mathrm{~min}$ and then centrifuged for $20 \mathrm{~min}$ at $20,000 \times \mathrm{g}$ at $4^{\circ} \mathrm{C}$. Supernatant was aliquoted into $1 \mathrm{ml}$ aliquots and frozen. Quantification of the lysates was performed by adding variable volumes of lysate to $20 \mu \mathrm{l}$ of $50 \%$ slurry of glutathione agarose (Sigma), adjusting the total volume to $1 \mathrm{ml}$ with lysis buffer (plus Triton X-100), and binding by rocking at RT for $15 \mathrm{~min}$. The agarose was washed twice by centrifuging for $10 \mathrm{~s}$, aspirating the supernatant off, and resuspending in $1 \mathrm{ml}$ of GST wash buffer (50 mu Tris-HCl, pH 8.2, 500 mm NaCl, 2 mм EDTA, 1\% Triton X-100, and $1 \mathrm{~mm}$ PMSF). Fusion protein was eluted by addition of $15 \mu$ l of protein loading buffer (5\% SDS, 5\% $\beta$-mercaptoethanol, and 5\% glycerol) and boiled for $2 \mathrm{~min}$. Samples were resolved by SDS-PAGE and Coomassie blue stained. BSA of known concentration was loaded onto the same gel to determine quantity of fusion protein bound to the agarose. Lysate volume yielding $500 \mathrm{ng}$ of fusion protein was bound to $20 \mu \mathrm{l}$ of glutathione agarose for each fusion protein as described above. After the wash, the affinity resin was equilibrated in $\beta \gamma$ binding buffer $(50 \mathrm{~mm}$ Tris- $\mathrm{HCl}, 150 \mathrm{~mm} \mathrm{NaCl}$, and $0.01 \%$ polyoxyethylene 9 lauryl ether) (Sigma). After equilibration, the agarose was resuspended in $20 \mu \mathrm{l}$ of $\beta \gamma$ binding buffer [final volume of $40 \mu \mathrm{l}$, final concentration of fusion protein of $200 \mathrm{~nm}$ (molecular weight of fusion protein $64 \mathrm{kDa}$ ), and $1.5 \mu \mathrm{l}$ of purified bovine brain $\beta \gamma(40 \mu \mathrm{g} / \mathrm{ml}$; Signal Transduction, San Diego, $\mathrm{CA})$ ] was added to the affinity agarose to give a final concentration of 40 nм $\beta \gamma$. The sample was mixed every $3 \mathrm{~min}$ for $30 \mathrm{~min}$ on ice. The fusion protein agarose was then washed four times in $1 \mathrm{ml}$ of $\beta \gamma$ binding buffer, resuspended in $15 \mu \mathrm{l}$ of protein load buffer, boiled for $2 \mathrm{~min}$, and resolved by SDS-PAGE. The primary antibody used for detection was $\alpha-\mathrm{G}_{\beta}$ (Santa Cruz Biotechnology, Santa Cruz, CA) at 1:250. After exposure, the blot was stripped and reprobed with $\alpha$-GST (Santa Cruz Biotechnology) to ensure equal quantity of fusion protein transfer.

Coimmunoprecipitation experiments. COS-7 cells were grown in 100 $\mathrm{mm}$ dishes and transfected with $2 \mu \mathrm{g}$ of each subunit indicated with Lipofectamine Plus (Invitrogen). Cells were washed three times with PBS (Sigma) and solubilized with $500 \mu \mathrm{l}$ of lysis buffer ( $100 \mathrm{~mm} \mathrm{NaCl}, 0.5 \%$ Igepal CA-350, 1 mm EDTA, $1 \mathrm{~mm}$ PMSF, and $1 \mu \mathrm{g} / \mathrm{ml}$ each aprotinin, leupeptin, and pepstatin) $48 \mathrm{~h}$ after transfection for $50 \mathrm{~min}$ rotating at $4^{\circ} \mathrm{C}$. Samples were centrifuged at $14,000 \times g$ for $20 \mathrm{~min}$ at $4^{\circ} \mathrm{C}$. The supernatant was removed and measured for protein concentration, and an aliquot was removed (lysate). The remaining supernatant was precleared with $40 \mu$ l of Protein G-Plus Agarose (Santa Cruz Biotechnology) or $40 \mu \mathrm{l}$ of Protein A-agarose (Sigma) for $20 \mathrm{~min}$ rotating at $4^{\circ} \mathrm{C}$, and subsequently the agarose was removed by centrifugation. The supernatant was incubated with antibody [rabbit $\alpha$-Kir.2.1 NT (generously provided by Dr. C. A. Vandenberg, University of California, Santa Barbara, CA)], mouse c-myc (9E10) antibody (Santa Cruz Biotechnology), mouse
FLAG (M2) antibody (Sigma), or rabbit HA antibody (Clontech) for $2 \mathrm{~h}$ at $4^{\circ} \mathrm{C}$. Protein G-Plus Agarose or Protein A-Agarose was added, and samples were rotated overnight at $4^{\circ} \mathrm{C}$. Samples were centrifuged for 5 $\min$ at $4^{\circ} \mathrm{C}$ to isolate agarose/antibody/protein complex. Immunoprecipitated samples were washed with PBS (containing 1 mM EDTA, 1 mM PMSF, and $1 \mu \mathrm{g} / \mathrm{ml}$ each aprotinin, leupeptin, and pepstatin), boiled in sample buffer (100 mu Tris-HCl, pH 6.8, 4\% SDS, 0.2\% bromophenol blue, and $20 \%$ glycerol), and resolved by SDS-PAGE. Mouse $\alpha$-GFP (Living Colors Av monoclonal antibody, JL-8; Clontech) was used to detect the tagged GIRK1 C-terminal constructs or the tagged Kir2.1 C-terminal constructs. Rabbit HA antibody (Clontech) was used to detect the tagged GIRK4 C-terminal constructs.

Immunostaining. Cells were grown on $25 \mathrm{~mm}$ coverslips and transiently transfected with $1 \mu \mathrm{g}$ of each subunit indicated with Lipofectamine Plus (Invitrogen). Cells were washed with PBS and fixed with $4 \%$ paraformaldehyde for $10 \mathrm{~min}$ at room temperature $48 \mathrm{~h}$ after transfection. When needed, cells were permeabilized with $0.1 \%$ Triton X-100 (in PBS) for $3 \mathrm{~min}$ at room temperature. Cells were blocked with $0.5 \%$ bovine serum albumin (Sigma) and $2 \%$ goat serum (Sigma) in $1 \times$ PBS for $30 \mathrm{~min}$ at room temperature. Cells were incubated with either rat $\alpha$-C-peptide at a 1:100 dilution or mouse $\alpha$-FLAG (Sigma) at a 1:1000 dilution for $1 \mathrm{~h}$ at room temperature, washed with $1 \times$ PBS for $30 \mathrm{~min}$, and incubated with FITC-conjugated goat $\alpha$-rat IgG (gift from Dr. J. Berkhardt, The University of Chicago), Alexa Fluor 488-conjugated goat $\alpha$-mouse IgG (Molecular Probes, Eugene, OR), or rhodamineconjugated goat $\alpha$-mouse IgG (Molecular Probes) for $1 \mathrm{~h}$ at room temperature. Cells without exposure to the primary antibody or nontransfected cells were used as control. The coverslips were mounted on a slide and observed using an Olympus Optical (Melville, NY) Fluoview 200 laser-scanning confocal microscope. Images were analyzed with $\mathrm{NIH}$ Image J software and MetaMorph (Universal Imaging Corporation, Downingtown, PA). Compiled confocal slices of the entire cell surface intensity was averaged per cell area (square micrometers) and used for quantification of surface protein expression.

\section{Results}

\section{C-Terminal deletion and mutant expression in oocytes}

To determine the regions critical for channel function, we examined the GIRK1 C terminus to identify possible domains involved in protein-protein interactions. The GIRK1 subunit consists of 501 amino acids and contains intracellular $\mathrm{N}$ and C termini (Dascal, 1997). Sequence alignment of all mammalian GIRK subunits (GIRK1-GIRK4) and the Kir2.1 subunit indicates a high degree of homology throughout the transmembrane regions and proximal C termini. Hydrophobic heptad repeats have been shown to form amphipathic structures that may interact with other proteins (Lupas et al., 1991; Lupas, 1996). The GIRK1 C terminus was found to contain several regions of hydrophobic residue repeats potentially forming interaction domains. Initial experiments were performed using two-microelectrode voltage clamp of oocytes injected with cRNA of the corresponding subunits indicated and a G-protein-coupled receptor, the muscarinic $\mathrm{m} 2$ receptor, which has been shown to couple to GIRK activation in the heart as well as heterologous expression in cell culture (Dascal et al., 1993; Kofuji et al., 1995). Expression of the GIRK1 subunit in oocytes results in the formation of a functional heterotetrameric channel consisting of the GIRK1 subunit and the endogenous GIRK5 oocyte subunit (Hedin et al., 1996). Using this strategy, we found that deletion of the C-terminal region (residues 330-384) of GIRK1 resulted in nonfunctional channel expression (data not shown) (Fig. $1 A$, sequence alignment). GIRK1 subunits expressed alone do not form functional channels in mammalian expression systems; consequently, GIRK1 subunits were tested by coexpression of the GIRK4 subunit. Coexpression 
A.

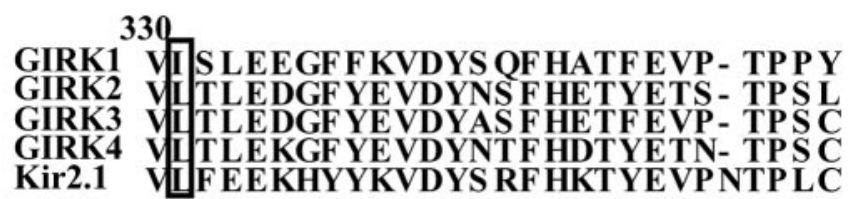

Kir2.1 UUF EEKHYYKVDYS RF HKTYEVPNTPLC

GIRK1 S VKEQEEMLLMS S PLI APAI TNS KERH

GIRK2 S AKE- . . .

GIRK3 SARE- . $\ldots \ldots \ldots$

GIRK4 CAKE- . . . . . . . . . . . . . .

Kir2.1 S ARDL . . . . . . . . . . . . . . .

B.

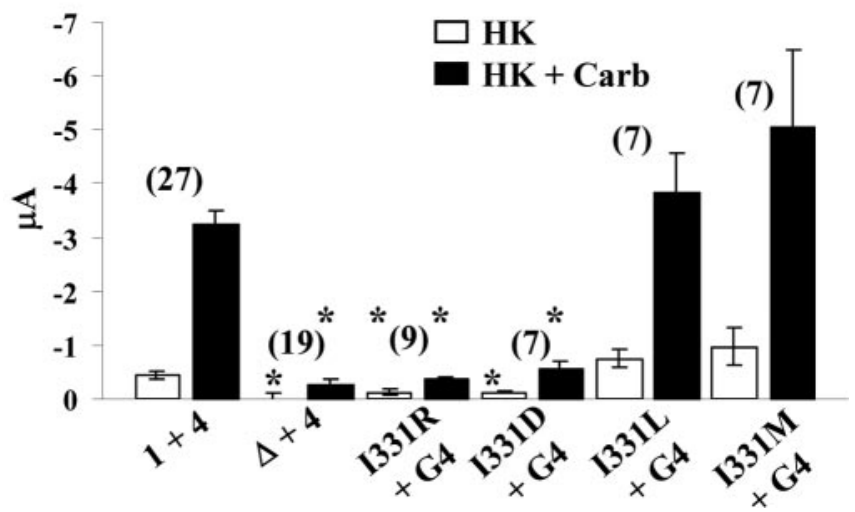

Figure 1. A, Human GIRK subunits (GIRK1-GIRK4) (GenBank accession numbers: GIRK1, P48549; GIRK2, NP_002231; GIRK3, Q92806; and GIRK4, P48544) and human Kir2.1 (GenBank accession number NP_000882) were aligned using Macintosh Megalign (Clustal method). The sequence presented is the region of GIRK1 330-384 identified as hydrophobic by sequence analysis. The mutated residue is boxed in the alignment. $\boldsymbol{B}$, GIRK functional analysis recorded in Xenopus 0ocytes. Average basal HKand agonist-induced (HK + Carb) currents (at $-150 \mathrm{mV} \pm$ SEM) recorded from oocytes injected with CRNA of the subunits indicated and $\mathrm{m} 2 \mathrm{R} .{ }^{*} p<0.05$ indicates significance for each group (HK or HK + Carb) compared with wild type.

of GIRK1 $\Delta 330-384$ with wild-type GIRK4 resulted in a complete loss of channel function compared with GIRK1 plus GIRK4, as summarized in Figure $1 B$ (peak HK current and HK plus Carbinduced current at $-150 \mathrm{mV} \pm$ SEM for G1 $+\mathrm{G} 4,-0.44 \pm 0.07$ and $-3.24 \pm 0.27 \mu \mathrm{A}$, respectively, and for G1 $\Delta 330-384+\mathrm{G} 4$, $-0.03 \pm 0.16$ and $-0.36 \pm 0.22 \mu \mathrm{A})$. To determine whether the proposed GIRK1 region represents an important functional domain (Fig. 1A), amino acids within the first seven residues were mutated to disrupt the hydrophobic nature of the proposed domain. Point mutations were introduced and assayed by twomicroelectrode voltage clamp after coinjection into oocytes with cRNA of the wild-type GIRK4 subunit and m2R. Mutations of GIRK1 V330 did not alter GIRK channel function (data not shown). However, mutations of isoleucine 331 to a charged residue lead to a similar loss of function (Fig. $1 B$; peak HK and HK + Carb current at $-150 \mathrm{mV} \pm \mathrm{SEM}$ for G1 I331D plus G4, $-0.12 \pm$ 0.02 and $-0.57 \pm 0.12 \mu \mathrm{A}$, and for G1 I331R $+\mathrm{G} 4,-0.12 \pm 0.05$ and $-0.35 \pm 0.04 \mu \mathrm{A}$, respectively). Mutation of the G1 I331 to a hydrophobic residue such as methionine or leucine did not significantly disrupt GIRK channel function (Fig. $1 B$; peak HK and $\mathrm{HK}+$ Carb current at $-150 \mathrm{mV} \pm$ SEM for G1 I331L + G4, $-0.75 \pm 0.17$ and $-3.83 \pm 0.72 \mu \mathrm{A}$, and for G1 I331M + G4, $-0.97 \pm 0.35$ and $-5.07 \pm 1.42 \mu \mathrm{A})$.
GIRK expression in COS-7 cells

To avoid the GIRK5 subunit and to investigate GIRK channel expression in a mammalian system, GIRK subunits and $\mathrm{m} 2 \mathrm{R}$ were expressed by transient expression in COS-7 cells. Coexpression of G1 $1 \Delta$, G4, and $\mathrm{m} 2 \mathrm{R}$ resulted in a loss of channel function, consistent with results obtained in oocytes (Fig. 2A,B). Peak HK and HK + Carb current density for G1 + G4 was $-20.81 \pm 6.70$ and $-42.47 \pm 8.66 \mathrm{pA} / \mathrm{pF}$ compared with $-4.07 \pm 2.30$ and $-5.25 \pm 2.27 \mathrm{pA} / \mathrm{pF}$ for G1 $\Delta+\mathrm{G} 4$ (Fig. $2 B$ ). Mutational analysis in oocyte experiments indicated that the isoleucine point mutation to a positively charged residue (G1 I331R) lead to a significant decrease in channel function similar to the deletion of the entire 330-384 region. Therefore, we focused on the effects of this particular mutation when expressed in COS-7 cells. Coexpression of G1 I331R and G4 also resulted in a decrease in functional channel expression (Fig. $2 A, B$; peak HK and HK + Carb current density for G1 I331R + G4, $-10.59 \pm 3.39$ and $-15.41 \pm$ $4.26 \mathrm{pA} / \mathrm{pF}$ ). To determine whether channel function was altered because of a global decrease in expression of the protein, Western blots of COS-7 whole-cell lysates transfected with subunits were performed to determine subunit expression. The G1 $\Delta$ and G1 I331R expressed to a similar degree as the wild-type G1 (Fig. 2C). Subunit expression and localization was also investigated by immunostaining of subunits in permeabilized COS-7 cells. Consistent with biochemical experiments, all subunits (including G4) were expressed (Figs. 2D, 3); however, the distribution of G1 $\Delta$ and G1 I331R appeared qualitatively slightly more perinuclear, indicating a possible alteration in subunit trafficking.

\section{Trafficking of GIRK subunits}

GIRK subunits have been shown to assemble as tetramers and localize to the membrane as a functional oligomer (for review, see $\mathrm{Ma}$ and Jan, 2002). Interaction between subunits also appears critical for proper expression of channels at the cell surface, as well as specific trafficking dependent on the subunits expressed (Kennedy et al., 1999; Ma et al., 2002; Mirshahi and Logothetis, 2004). To determine whether the mutation of the G1 isoleucine resulted in a possible disruption of subunit localization to the membrane, a FLAG epitope was inserted into the extracellular region of the GIRK1 subunit P-loop. G1-FLAG coexpressed with the G4 subunit and $\mathrm{m} 2$ receptor in COS-7 cells did not alter the level of protein expression or channel function (data not shown). Surface expression of the G1-FLAG subunit and point-mutant subunit (G1 I331R-FLAG) when expressed alone and when coexpression with G4 was analyzed using COS-7 cells. Permeabilized COS-7 cells exhibited a diffuse distribution of G1-FLAG when expressed alone and colocalization when expressed with G4-EGFP. Similar distribution was seen with expression of G1 I331R-FLAG alone and when coexpressed with G4-EGFP (Fig. 3, top row). We monitored surface expression of the epitope-tagged subunits in nonpermeabilized COS-7 cells transfected with the indicated subunits. When expressed alone, neither the G1-FLAG nor the G1 I331R-FLAG were positive for surface expression, consistent with results obtained by Kennedy et al. (1999) that demonstrated a lack of GIRK1 subunit surface expression when expressed alone. However, as a result of coexpression of the wildtype G4, both the G1-FLAG and G1 I331R-FLAG exhibited a punctate surface staining (Fig. 3, bottom row). Quantification of total surface intensity for the G1-FLAG was not different from the 
G1 I331R-FLAG (data not shown). Trafficking of the point mutation (G1 I331RFLAG) to the plasma membrane was unaltered.

\section{Homologous point mutation in GIRK4 and non-G-protein-dependent inward rectifier}

In an effort to demonstrate whether the hydrophobic residue (I331) was of unique importance for a functional G1 subunit or whether it had universal functional significance among GIRK subunits, a homologous point mutation in the G4 subunit, L337R, was made (Fig. 1). The homologous point mutation in the GIRK4 subunit (L337R) also resulted in a reduction in GIRK channel function when coexpressed with the wild-type G1 subunit and $\mathrm{m} 2 \mathrm{R}$ (Fig. 4A) (peak HK and HK + Carb current density for $\mathrm{G} 1+\mathrm{G} 4,-20.81 \pm 6.70$ and $-42.47 \pm 8.66 \mathrm{pA} / \mathrm{pF}$, and for $\mathrm{G} 1+$ G4 L337R, $-4.98 \pm 1.29$ and $-5.93 \pm$ $1.53 \mathrm{pA} / \mathrm{pF}$ ). To determine whether the decrease in channel function was dependent on $\mathrm{G}_{\beta \gamma}$ binding, the homologous hydrophobic residue in the non-G-proteindependent inward rectifier Kir2.1 was mutated to a positively charged arginine (Fig. 1). Kir2.1 subunits form homomeric tetramers and are constitutively active when expressed in heterologous expression systems. Expression of the Kir2.1 L330R resulted in a significant decrease in channel function, as shown in Figure $4 B$ (current density) (peak current at -160 $\mathrm{mV},-0.03 \pm 0.01 \mathrm{nA} / \mathrm{pF}$ ) compared with wild-type Kir2.1 channel function $(-0.55 \pm 0.17 \mathrm{nA} / \mathrm{pF})$. To test for direct binding, GST fusion proteins of the G1 C terminus and point mutations were made and tested for $\beta \gamma$ binding. The amount of interacting $\beta$ subunit was similar for wild-type GST-G1 CT and GST-G1 CT point mutations (Fig. 5).

Arginine mutation disrupts intracellular domain association Because mutated subunits affected channel function in multiple GIRK subunits and different inward rectifier families, we set out to determine whether the arginine mutation in the $\mathrm{C}$ terminus of GIRK1 would disrupt association between the intracellular Nand C-terminal domains, indicating a possible conformational importance of the C-terminal residue in context of channel function. Localization of the I331 residue in the GIRK1 subunit structure indicates that the residue lies between adjacent $\mathrm{C}$ termini and the $\mathrm{N}$ terminus within a subunit (Nishida and MacKinnon, 2002) (Fig. 6A,B). Although the $\mathrm{I} 331$ homologous residue of the KirBacl.1 subunit is a methionine (by sequence alignment), the residue lies adjacent to an unresolved region and the interacting region between the $\mathrm{N}$ terminus of one subunit and the $\mathrm{C}$ terminus of the adjacent subunit (Kuo et al., 2003) (Fig. 6C). We first examined the association of the full-length subunits by coimmu-
C.

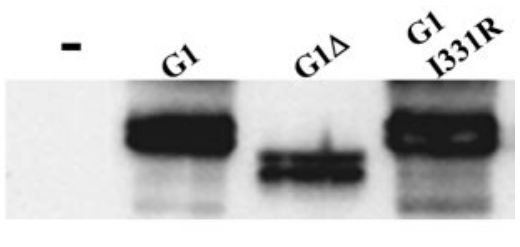

D.
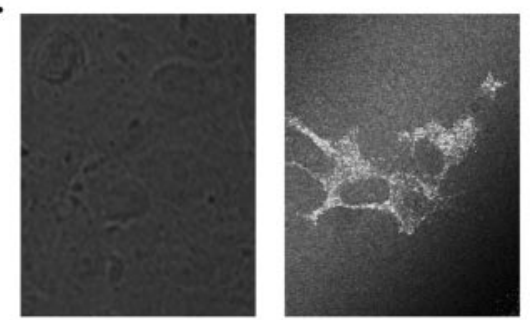

G1
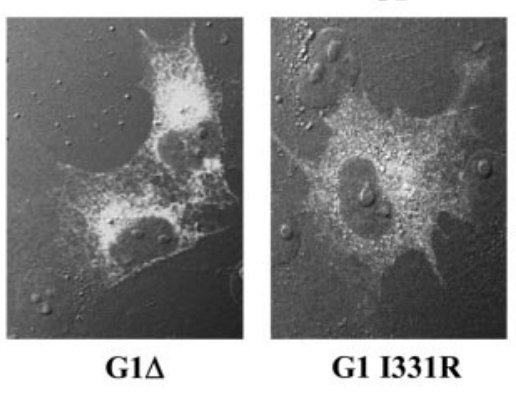

G1 I331R

Figure 2. GIRK subunit protein and functional expression in COS-7 cells. $A$, Representative current traces recorded from COS-7 per picofarads) recorded from COS-7 cells $48-72 \mathrm{~h}$ after transient transfection with the subunits indicated, $\mathrm{m} 2 \mathrm{R}$, and pEGFP. Peak 列 $-160 \mathrm{mV}$ were barium subtracted and determined by current density $\left({ }^{*} p<0.05\right.$, compared with wild-type HK or tagged with the C-peptide of the insulin gene ( $59-62 \mathrm{kDa}$ ) (see Materials and Methods). Membranes were blotted with $\alpha$ - $C$ Cells were permeabilized and subsequently probed with $\alpha$-C-peptide antibody and an FITC-conjugated $\alpha$-rat secondary antibody and visualized using the confocal microscope. Images are $0.5 \mu \mathrm{m}$ slices (60× objective).

noprecipitation. G1 $\Delta$ and G1 I331R associated with the G4-GFP to a similar extent as the wild-type G1 (Fig. 7A). Although the subunits still appear to associate, we reasoned that the molecular interactions between the intracellular regions of the subunits may be affected. To test for intracellular domain association, taggedconstructs of the $\mathrm{N}$ - and $\mathrm{C}$-terminal domain were made and expressed in COS-7 cells. G1 NT-myc (residues 1-83) and YFP-G1 CT (including second transmembrane domain, residues 158-501) were coexpressed in COS-7 cells. G1 NT-myc was coimmunoprecipitated with the YFP-G1 CT (Fig. 7B). Coexpression of the G1 NT-myc with either the YFP-G1 CT $\Delta$ or YFP-G1 CT I331R failed to coimmunoprecipitate and resulted in a loss of association (Fig. 7B, lanes 3-6). The association between the G1 NT-myc and YFP-G1 CT mutations I331M or I331L was unaffected (data not shown).

Next, we set out to determine whether the associations between subunits were affected as a result of residue mutation. We have shown that the $\mathrm{N}$ - and C-terminal association of the GIRK1 subunit is disrupted after mutation of the I331 to an arginine. The mutation of the homologous GIRK4 residue L337R also resulted in decreased coimmunoprecipitation with the G4 NT-FLAG, although the wild-type association was relatively weak (Fig. $8 \mathrm{~A}$, 


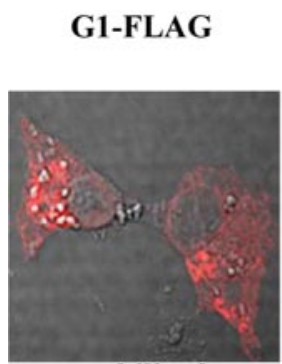

permeabilized

G1-FLAG

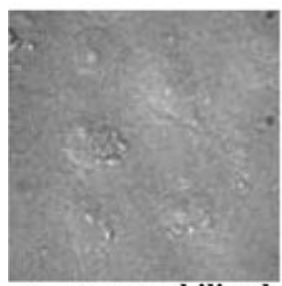

non-permeabilized

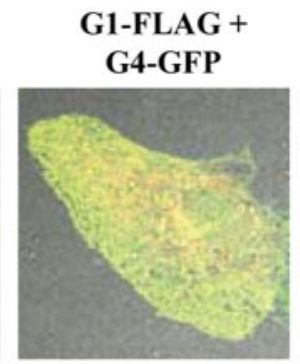

G1-FLAG + G4

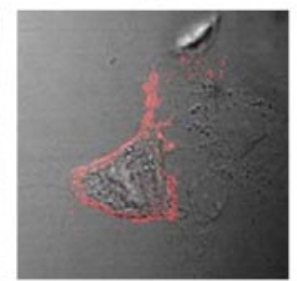

G1 I331R-FLAG

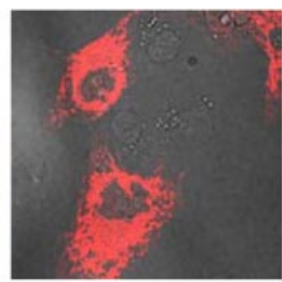

G1 I331R-FLAG

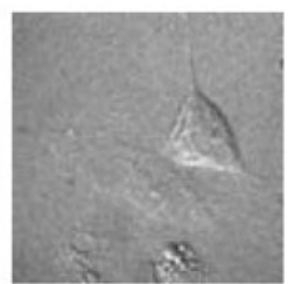

G1 I331R-FLAG + G4-GFP

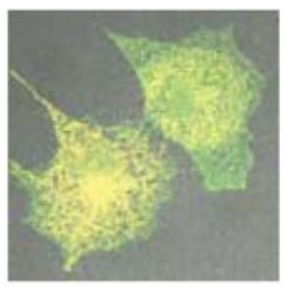

G1 I331R-FLAG + G4

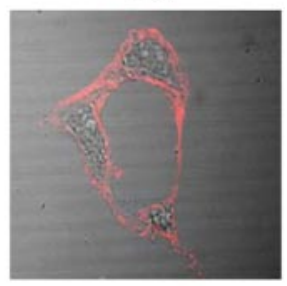

Figure 3. Trafficking of GIRK1 subunits is unaffected by mutation. COS-7 cells were either permeabilized or nonpermeabilized and probed with $\alpha$-FLAG antibody to detect FLAG-tagged GIRK1 wild-type or mutant subunit expression. Top row, Permeabilized cells were transfected with only the GIRK1 subunit indicated or in addition to the GIRK4-GFP to monitor protein localization. Cotransfected cells were probed with the $\alpha$-FLAG antibody and a rhodamine-conjugated goat $\alpha$-mouse secondary antibody. GIRK1-alone transfected cells were probed with $\alpha$-FLAG antibody and an Alexa Fluor 488-conjugated goat $\alpha$-mouse secondary antibody (fluorescence is indicated in red for consistency). Images are $0.5 \mu \mathrm{m}$ slices. Bottom row, Nonpermeabilized cells were transfected with the GIRK1-FLAG subunit indicated and an untagged GIRK4 subunit and subsequently probed with the $\alpha$-FLAG antibody and Alexa Fluor 488-conjugated secondary antibody to monitor surface expression of GIRK1-FLAG (surface protein expression is represented in red for consistency). Images are $0.5 \mu \mathrm{m}$ slices.

top). We next examined the association of $\mathrm{N}$ - and C-terminal domains of possible adjacent GIRK subunit domains (i.e., G4 NT and G1 CT). The G4 NT coimmunoprecipitated the G1 CT and mutation of the G1 CT, I331R, resulted in the loss of association (Fig. $8 \mathrm{~A}$, middle). The converse coimmunoprecipitation experiment between the G1 NT and G4 CT also resulted in an association that was reduced as a result of mutation of the G4 CT L337R, but to a weaker degree than the G1 CT (Fig. $8 \mathrm{~A}$, bottom). $\mathrm{C}$-Terminal association between the subunit intracellular domains was unaffected by mutation (Fig. $8 B$, top and middle). Because mutation of the hydrophobic residue in this region affected Kir2.1 channel function in addition to GIRK channels, we tested the Kir2.1 N- and C-terminal domains for association and found that the L330R mutation did not disrupt the association of the $\mathrm{N}$ - and C-terminal domains of Kir2.1 (Fig. 8C).

\section{Mutation of N-terminal residue decreases channel function}

Structural data pinpoint possible residues that may be important in interactions between $\mathrm{N}$ - and C-terminal domains. The GIRK1 I331 appears to lie in a hydrophobic pocket in proximity to several C-terminal residues of the adjacent subunit, as well as the $\mathrm{N}$ terminus of the subunit (Fig. 6B). We speculated that the GIRK1 N-terminal phenylalanine residue (F46) was a possible candidate for hydrophobic interaction with the I331. Other possible interacting residues lie in the adjacent C-terminal domain, as indicated in the GIRK1 subunit structure. However, because $\mathrm{N}$ - and $\mathrm{C}$-terminal associations appeared to be more critical than the C-termini associations in our studies, we focused on mutations within the GIRK1 N terminus. Mutation of the F46 to an arginine or an aspartate resulted in the mixed ability to coimmunoprecipitate with the wild-type GIRK1 CT (Fig. 9A). The G1 NT F46R appeared to weakly interact with the G1 CT, whereas the G1 NT F46D mutation did not associate with the G1 CT domain (Fig. 9A). Like the G1 I331R subunit, the G1 F46 mutations did not inhibit the expression of the subunit at the cell surface (Fig. 9B). Because the GIRK1 F46 mutation did result in a decrease in the interaction between the GIRK1 N and C termini, we also examined the mutational effects on channel function. $\mathrm{Mu}-$ tation of the full-length subunit F46 to either an aspartate or arginine coexpressed with GIRK 4 resulted in disruption of channel function (Fig. 9C,D; peak $\mathrm{HK}$ and $\mathrm{HK}+$ Carb current density for $\mathrm{G} 1+\mathrm{G} 4,-20.81 \pm 6.70$ and $-42.47 \pm 8.66 \mathrm{pA} / \mathrm{pF}$, for $\mathrm{G} 1$ $\mathrm{F} 46 \mathrm{R}+\mathrm{G} 4,-6.33 \pm 2.48$ and $-15.58 \pm 4.62 \mathrm{pA} / \mathrm{pF}$, and for $\mathrm{G} 1$ $\mathrm{F} 46 \mathrm{D}+\mathrm{G} 4,-2.98 \pm 1.71$ and $-2.84 \pm 1.56 \mathrm{pA} / \mathrm{pF})$. Mutation of another hydrophobic residue, F46, within this interaction region of the termini resulted in a similar decrease in functional channel expression, as well as decreased association between intracellular domains.
A.

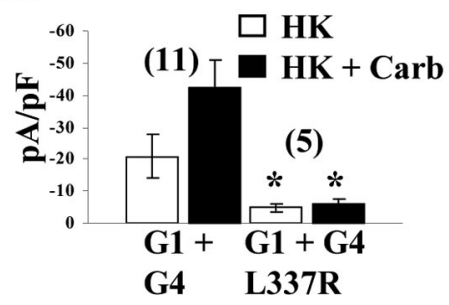

B.

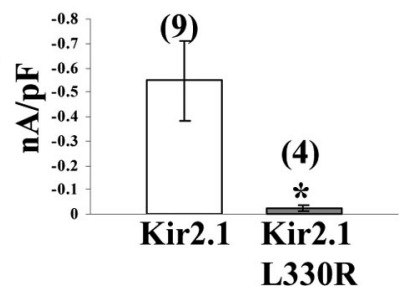

Figure 4. Homologous GIRK4 and Kir2.1 mutations disrupt channel function. $A$, Average HK and HK + Carb peak currents at $-160 \mathrm{mV}$ were normalized per cell $\left({ }^{*} p<0.05\right)$. B, Basal currents were recorded from COS-7 cells transfected with the indicated subunit and $p E G F P$. Summary of peak basal currents (at $-160 \mathrm{mV}$ ) recorded from Kir2.1 and Kir2.1 L330R $\left({ }^{*} p<0.05\right)$ is shown.
Figure 5. G-protein binding to Kir cytoplasmic domains. GST fusion proteins of the C-terminal domains of $\mathrm{G} 1$ wild type, mutants, Kir2.1, or $\beta$ ARK were tested for $\mathrm{G}_{\beta}$ association. The blot was probed with $\alpha-G_{\beta}$ and secondary antibody and visualized with chemiluminescence. 


\section{Discussion}

Mutations do not alter surface subunit expression

In this study, we examined the functional importance of a hydrophobic region in the cytoplasmic termini, particularly of GIRK subunits. Channel subunit mutations may affect channel function by altering protein expression or subunit localization. The mutation GIRK1 I331R resulted in comparable subunit expression and did not alter cell surface expression. However, we cannot exclude the possibility of a modification in channel subunit composition at the plasma membrane. In the heart, GIRK1 and GIRK4 subunits are thought to comprise functional GIRK channels in a 1:1 stoichiometry (Corey et al., 1998). Several subunit compositions form functional channels in the CNS both as homomultimers and heteromultimers of GIRK subunits (Krapivinsky et al., 1995b; Inanobe et al., 1999; Jelacic et al., 2000; Leaney, 2003). We have shown that the arrangement of the GIRK1 subunit relative to the GIRK2 weaver subunit within a given channel dictated functional channel properties (Hou et al., 1999). It has been demonstrated that the GIRK4 subunit contains forward trafficking motifs that result in surface localization of other GIRK subunits (Ma et al., 2002). Our results suggest that the GIRK1 I331R mutant subunit does not disrupt overall recognition between the GIRK1 and GIRK4 subunits and furthermore does not appear to inhibit channel assembly and membrane localization.

\section{C-terminal domain mutations alter channel function}

Mutation of GIRK1 I331 or the homologous GIRK4 and Kir2.1 residues resulted in a decrease in channel function. It has been well established that GIRK channels are activated during binding of G-protein $\beta \gamma$ subunits (Logothetis et al., 1987; Reuveny et al., 1994; Huang et al., 1995). The G-protein complex appears to bind several GIRK subunit regions of the intracellular $\mathrm{N}$ and $\mathrm{C}$ termini, including a portion of the hydrophobic region identified in this study (Huang et al., 1995, 1997; He et al., 1999, 2002; Ivanina et al., 2003). Several studies have shown that the bending of the TM2 likely results in the opening of the pore, much like the gating mechanism deduced from structural studies of the bacterial $\mathrm{Ca}^{2+}$-activated $\mathrm{K}^{+}$channel MthK (Methanobacterium thermo-autotrophicum) $\mathrm{K}^{+}$channel (Sadja et al., 2001; Jiang et al., 2002; Jin et al., 2002). Fluorescence resonance energy transfer (FRET) analysis demonstrated that the intracellular domains of the GIRK1 and GIRK4 subunits are rearranged during activation (Riven et al., 2003). In the KirBac1.1 crystal structure, cytoplasmic domains are linked to TM domains via linkers and an amphipathic helix, which the authors predict are involved in the coupling between movement of intracellular and TM domains (Kuo et al., 2003). Together, these results support the hypothesis that rearrangements of intracellular domains translate a signal that results in channel opening.
C.

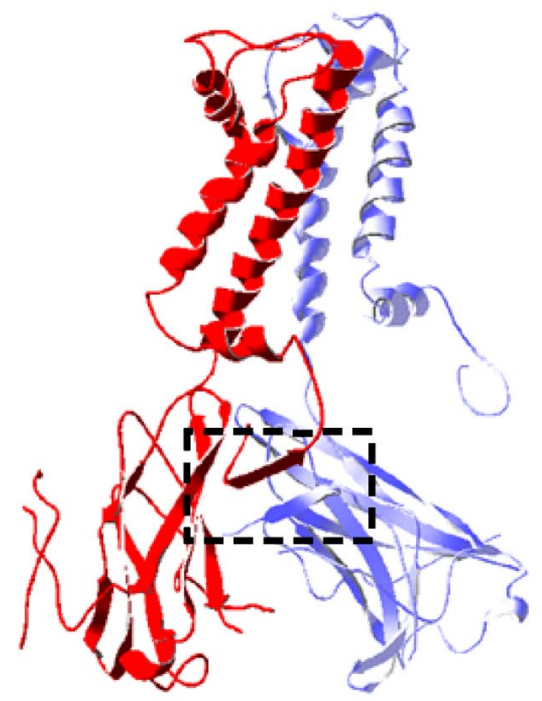

Because the C-terminal domain is well conserved among inward rectifiers, we reasoned that the mutation might result in a defect in the general gating transduction mechanism independent of $\mathrm{G}_{\beta \gamma}$ binding. Our data, as well as the data of Chen et al. (2002), which demonstrated that the mutation E304A resulted in a disruption of channel function in both GIRK and Kir2.1 channels containing the homologous mutation, support the latter hypothesis. Other residues within the $\mathrm{C}$ terminus of GIRK subunits have also been shown to mediate function. The mutation GIRK4 L339E (and GIRK1 L333E) resulted in a reduction in agonist G-protein-dependent current expression and a significant reduction in direct $G_{\beta \gamma}$ binding. The authors concluded that this residue (the homologous Kir2.1 residue is a glutamate) is responsible for receptor stimulated $\mathrm{G}_{\beta \gamma}$ activation (He et al., 1999). Functionally, GIRK1 L333E/GIRK2 L344E channels show a decrease in basal current and a significant loss in agonist-induced GIRK current with a smaller decrease in $\mathrm{G}_{\beta \gamma}$ binding (Ivanina et al., 2003). Recently, Finley et al. (2004) demonstrated a similar loss in GIRK2L344E/G347H channel function and little change in $\mathrm{G}_{\beta \gamma}$ binding to the double-mutated channel. In this study, we did not detect a difference in $\mathrm{G}_{\beta \gamma}$ binding to the mutant domains. However, we found a decrease in both agonist-independent and carbachol-dependent GIRK channel activation and disruption of the non-G-protein-dependent activation of Kir2.1. We have not further characterized differences between agonist-independent and -dependent decreases in channel function because the mutation alters function in both channel types. Furthermore, our results indicate that a disruption in $\mathrm{G}_{\beta \gamma}$ binding does not underlie 
A.

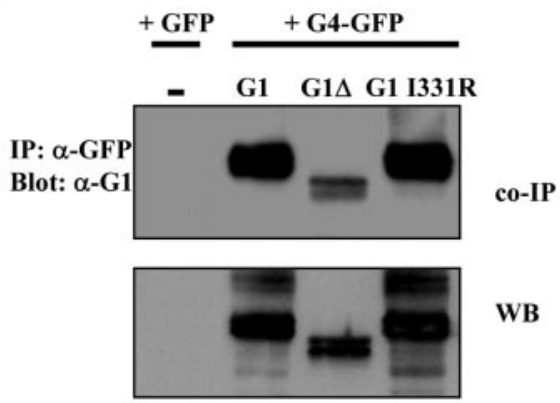

B.

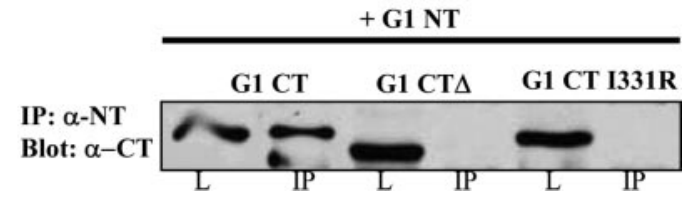

Figure 7. GIRK1 $\Delta 330-384$ and I331R disrupted $\mathrm{N}$ - and C-termini association. $\boldsymbol{A}$, Fulllength subunits were expressed in COS-7 cells, and subunit protein expression was detected with $\alpha$-GIRK1 antibody. Immunoprecipitation of the G4-GFP resulted in the coimmunoprecipitation of the GIRK1, GIRK1 $\Delta$, and GIRK1 I331R subunit $(n=3) \boldsymbol{B}$, GIRK intracellular domain constructs were coexpressed in COS-7 cells as indicated, and samples were loaded on SDS-PAGE before immunoprecipitation [lysate (L)] and after coimmunoprecipitation (IP). All samples were immunoprecipitated with the $\alpha$-myc antibody [recognizing the G1 NT-myc (for clarity, indicated as $\alpha$-NT)], and blots were probed with $\alpha$-GFP antibody [recognizing YFP-G1 (T and YFP-G1 CT I331R, $68 \mathrm{kDa}(n=13)$, and YFP-G1 CT $\Delta, 62 \mathrm{kDa}(n=3)$ (indicated as $\alpha$-CT)]. The lower band (in IP lanes) is attributable to the heavy-chain IgG. WB, Western blot.

A.
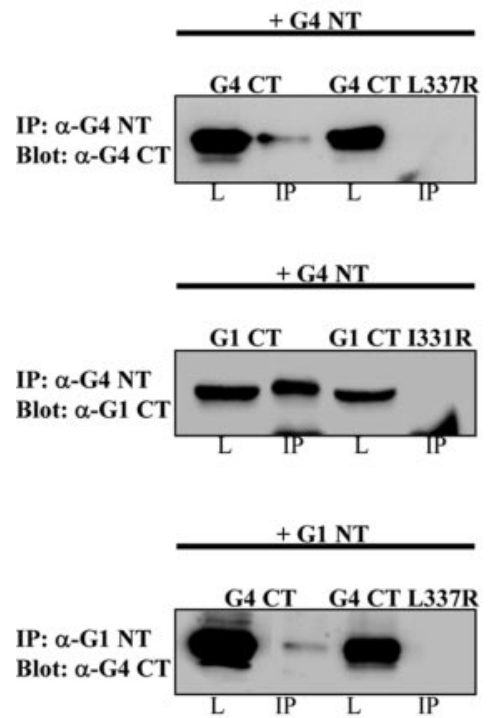

B.

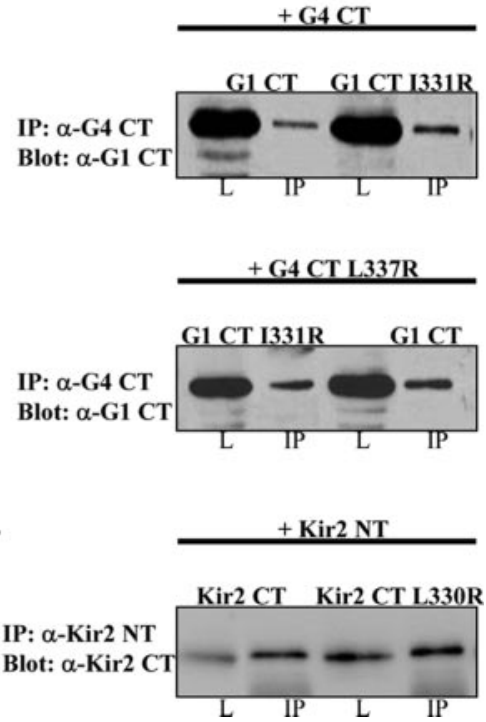

Figure 8. $\quad \mathrm{N}$ - and C-Termini association is decreased in C-terminal mutants. $\boldsymbol{A}$, GIRK intracellular domain constructs were coexpressed in COS-7 cells as indicated, and samples were loaded on SDS-PAGE before immunoprecipitation [lysate (L)] and after coimmunoprecipitation (IP). All samples were immunoprecipitated with either the $\alpha$-myc antibody [recognizing the G1 NT-myc (for clarity, indicated as $\alpha$-G1 NT)] or the $\alpha$-FLAG antibody [recognizing the G4 NT-FLAG (for clarity, indicated as $\alpha$-G4 NT)], and blots were probed with either the $\alpha$-GFP antibody [recognizing YFP-G1 CT and YFP-G1 CT I331R, $68 \mathrm{kDa}$ (for clarity, indicated as $\alpha$-G1 CT)] or the $\alpha$-HA antibody [recognizing G4 CT-HA, $27 \mathrm{kDa}$ (for clarity, indicated as $\alpha-\mathrm{G} 4 \mathrm{CT}$ ); $n=5$ ]. $\boldsymbol{B}, \mathrm{GIRK}$ intracellular domain constructs were coexpressed in COS-7 cells as indicated, and samples were loaded on SDS-PAGE before immunoprecipitation [lysate (L)] and after coimmunoprecipitation (IP). All samples were immunoprecipitated with the $\alpha$-HA antibody [recognizing the G4CT-HA (for clarity, indicated as $\alpha$-G4 (T)], and blots were probed with the $\alpha$-GFP antibody [recognizing YFP-G1 CT and YFP-G1 CT I331R, 68 kDa (for clarity, indicated as $\alpha$-G1 (T); $n=3]$. C, Kir2.1 intracellular domain constructs were coexpressed in COS-7 cells as indicated, and samples were loaded on SDS-PAGE before immunoprecipitation [lysate (L)] and after coimmunoprecipitation (IP). All samples were immunoprecipitated with the $\alpha$-Kir2.1 NT antibody [recognizing the Kir2.1 NT-myc (for clarity, indicated as $\alpha$-Kir2 NT)], and blots were probed with the $\alpha$-GFP antibody [recognizing YFP-Kir2.1 CT, 59 kDa (for clarity, indicated as $\alpha$-Kir CT); $n=3$ ]. the functional effects, unlike previous studies examining the role of various residues in this region. Although we cannot rule out the possibility that $\mathrm{G}_{\beta \gamma}$ binding is reduced for the GIRK1 I331R subunit in an assembled, intact channel, a similar effect in Kir2.1 argues that it is highly likely that the structural integrity of this region is involved in the transduction event resulting in channel gang. The change in structural interactions involving 1331 (or Ling indirectly alter $\mathrm{G}_{\beta \gamma}$ binding to residues identified in previous studies. Our results implicate an additional

Structural implications support a role in termini interactions The recent crystal structure of linked GIRK1 subunit intracellular domains suggests that the GIRK1 C-terminal region examined in this study is involved in $\mathrm{N}$ - and $\mathrm{C}$-termini interactions. GIRK1 I331 lies in close proximity to the $\beta$-sheet formed between the $\mathrm{N}$ and $\mathrm{C}$ termini of one subunit and other residues of an adjacent GIRK1 subunit (Nishida and MacKinnon, 2002). GIRK subunits are highly homologous throughout this region, suggesting a similar structure in the assembled heteromultimeric channel. The KirBacl.1 crystal structure includes intracellular and transmembrane domains in which the $\mathrm{N}$ terminus of one subunit forms a $\beta$-sheet with the $C$ terminus of the adjacent subunit. Regardless of which structure more accurately depicts the true termini interaction, it is evident in both structures that the interaction between adjacent $\mathrm{N}$ and $\mathrm{C}$ termini is likely to play a role in channel gating (Kuo et al., 2003). Finley et al. (2004) also postulated that interactions between GIRK subunit C-terminal regions (GIRK2 residues 344347 ) and the adjacent subunit $\mathrm{N}$-terminal domain are involved in activation. It has been shown that the GIRK1 TM domains and $\mathrm{C}$ terminus are important for interaction (Woodward et al., 1997). Proteinprotein interactions between purified components of the intracellular GIRK1 and GIRK4 termini have also been demonstrated (Huang et al., 1997). Because the loss of channel function appears to be dependent on a hydrophobic residue that maps to an interacting region between cytoplasmic domains in the GIRK1 subunit structure, we examined possible associations between intracellular domains of the subunits. Although our studies do not measure direct interactions, they clearly showed that the GIRK1 N and C termini coimmunoprecipitated and that the mutation significantly decreased this association. In addition, $\mathrm{N}$ - and C-terminal association within the GIRK4 subunit or between subunits is decreased when mutated, but the $\mathrm{C}$ termini associations are not altered. Although these results are a product of determining domain associations in an expression system, the results mirror the loss of channel function.

Several possibilities may account for both the decrease in association of cytoplasmic domains and a disruption in channel function. In an assembled channel, the I331 may directly interact with 
other adjacent $\mathrm{N}$-terminal residues (such as F46) or the adjacent C-terminal subunit. Mutations may disrupt direct interactions resulting in channel dysfunction. Alternatively, the mutation may disrupt the overall conformation of the region hindering the interaction of other proximal residues that then directly interact with the $\mathrm{N}$ terminus. Interactions between $\mathrm{N}$ - and C-terminal domains of the Kir6.2 subunit have been localized to a region in the $\mathrm{N}$ terminus that, when mutated, resulted in a decrease in channel function (Tucker and Ashcroft, 1999). The $\mathrm{N}$-terminal residue identified is a conserved glycine and maps to a similar region of interest. Also, the Kir6.2 $\mathrm{N}$ terminus binds to several C-terminal regions, including a domain that contains the homologous GIRK1 I331 residue (Jones et al., 2001). Another possibility is that the arginine mutation establishes an alternative interaction that stabilizes the channel in a closed conformation. We speculate that the intracellular interface between termini of individual subunits and among adjacent subunits comprises a portion of the pathway of conformational repositioning that eventually results in opening of the pore.

\section{Hydrophobic nature is critical for channel function}

Our results argue strongly that the conformational arrangement of the isoleucine is highly important and suggests a general mechanism for the dysfunction of channel activation. Moreover, because Kir2.1 channels are constitutively open, mutation of this conserved region indicates that the mutated residue plays a general role in activation. Interactions between intracellular domains of $\mathrm{K}^{+}$channels have been well studied. $\mathrm{pH}$-dependent gating of Kir1.1 [ROMK (renal outer medulla $\mathrm{K}^{+}$channel)] is thought to involve altered movements of the $\mathrm{N}$ and $\mathrm{C}$ termini (Schulte et al., 1998). Also, protons appear to alter the N- and C-terminal interactions of purified domains of the Kir2.3 subunit (Qu et al., 2000). FRET analysis of GIRK channel activation supports a role for the movement of the $\mathrm{C}$-terminal domains relative to the N-terminal domains (Riven et al., 2003). Several studies of Kir6.2 have also indicated that modulators can alter the relative interactions between intracellular domains (Lippiat et al., 2002; Tsuboi et al., 2004). A general disruption of termini domain interactions would explain the similar loss of function for both the G-proteindependent and -independent inward rectifiers. We identified a $\mathrm{N}$-terminal residue, F46, that is in close proximity to the I331 in the GIRK1 subunit structure and, when mutated to a charged residue, also resulted in a decrease in channel function. The association between mutated G1 NT and CT domains was decreased for the F46D mutation and a weak association for F46R. However, if the association between the intracellular $\mathrm{N}$ - and C-terminal domains is an essential component of the conformational changes leading to both activation in the GIRK channel and maintaining the open state of the Kir2.1 channel, we would expect a decrease in the association of the $\mathrm{N}$ - and C-terminal intracellular domains of the Kir2.1, which we did not observe. Therefore, although similar mutations affect the function of both channels, the conformational changes in the cytoplasmic domains are most likely different.

Together, our results suggest that the structural integrity of this specific region is important for channel function and that the introduction of a charged residue in this hydrophobic region destabilizes the structure. Mutational studies that compare the effects of hydrophobic substitutions will provide additional information on the nature of the interacting region. Additional studies analyzing the interaction between the intracellular components of the GIRK channel and other inward rectifiers will shed light on the importance of these intracellular domain interactions.

\section{References}

Chen L, Kawano T, Bajic S, Kaziro Y, Itoh H, Art JJ, Nakajima Y, Nakajima S (2002) A glutamate residue at the $C$ terminus regulates activity of inward rectifier $\mathrm{K}^{+}$channels: implication for Andersen's syndrome. Proc Natl Acad Sci USA 99:8430-8435.

Corey S, Clapham DE (1998) Identification of native atrial G-proteinregulated inwardly rectifying $\mathrm{K}^{+}$(GIRK4) channel homomultimers. J Biol Chem 273:27499-27504.

Corey S, Krapivinsky G, Krapivinsky L, Clapham DE (1998) Number and stoichiometry of subunits in the native atrial G-protein-gated $\mathrm{K}^{+}$channel, $\mathrm{I}_{\text {KACh. }}$ J Biol Chem 273:5271-5278. 
Dascal N (1997) Signalling via the G protein-activated $\mathrm{K}^{+}$channels. Cell Signal 9:551-573.

Dascal N, Schreibmayer W, Lim NF, Wang W, Chavkin C, DiMagno L, Labarca C, Kieffer BL, Gaveriaux-Ruff C, Trollinger D, Lester HA, Davidson N (1993) Atrial G protein-activated $\mathrm{K}^{+}$channel: expression cloning and molecular properties. Proc Natl Acad Sci USA 90:10235-10239.

Finley M, Arrabit C, Fowler C, Suen KF, Slesinger PA (2004) $\beta \mathrm{L}-\beta \mathrm{M}$ loop in the $\mathrm{C}$-terminal domain of GIRK channels is important for $\mathrm{G} \beta \gamma$ activation. J Physiol (Lond) 555:643-657.

He C, Zhang H, Mirshahi T, Logothetis DE (1999) Identification of a potassium channel site that interacts with $\mathrm{G}$ protein $\beta \gamma$ subunits to mediate agonist-induced signaling. J Biol Chem 274:12517-12524.

He C, Yan X, Zhang H, Mirshahi T, Jin T, Huang A, Logothetis D (2002) Identification of critical residues controlling $\mathrm{G}$ protein-gated inwardly rectifying $\mathrm{K}^{+}$channel activity through interactions with the $\beta \gamma$ subunits of $\mathrm{G}$ proteins. J Biol Chem 277:6088 -6096.

Hedin KE, Lim NF, Clapham DE (1996) Cloning of a Xenopus laevis inwardly rectifying $\mathrm{K}^{+}$channel subunit that permits GIRK1 expression of $\mathrm{I}_{\text {KACh }}$ currents in oocytes. Neuron 16:423-429.

Ho IH, Murrell-Lagnado RD (1999) Molecular mechanism for sodiumdependent activation of $\mathrm{G}$ protein-gated $\mathrm{K}^{+}$channels. J Physiol (Lond) 520:645-651.

Hou P, Yan S, Tang W, Nelson DJ (1999) The inwardly rectifying $\mathrm{K}^{+}$channel subunit GIRK1 rescues the GIRK2 weaver phenotype. J Neurosci 19:8327-8336.

Huang C-L, Slesinger PA, Casey PJ, Jan YN, Jan LY (1995) Evidence that direct binding of $\mathrm{G}_{\beta \gamma}$ to the GIRK1 G protein-gated inwardly rectifying $\mathrm{K}^{+}$channel is important for channel activation. Neuron 15:1133-1143.

Huang C-L, Jan YN, Jan LY (1997) Binding of the G protein $\beta \gamma$ subunit to multiple regions of $\mathrm{G}$ protein-gated inward-rectifying $\mathrm{K}^{+}$channels. FEBS Lett 405:291-298.

Inanobe A, Morishige K-I, Takahashi N, Ito H, Yamada M, Takumi T, Nishina H, Takahashi K, Kanaho Y, Katada T, Kurachi Y (1995) G $\beta \gamma$ directly binds to the carboxyl terminus of the $\mathrm{G}$ protein-gated muscarinic $\mathrm{K}^{+}$channel, GIRK1. Biochem Biophys Res Commun 212:1022-1028.

Inanobe A, Yoshimoto Y, Horio Y, Morishige KI, Hibino H, Matsumoto S, Tokunaga Y, Maeda T, Hata Y, Takai Y, Kurachi Y (1999) Characterization of G-protein-gated $\mathrm{K}^{+}$channels composed of Kir3.2 subunits in dopaminergic neurons of the substantia nigra. J Neurosci 19:1006-1017.

Ivanina T, Rishal I, Varon D, Mullner C, Frohnwieser-Steinecke B, Schreibmayer W, Dessauer CW, Dascal N (2003) Mapping the Gbeta gammabinding sites in GIRK1 and GIRK2 subunits of the G protein-activated $\mathrm{K}^{+}$channel. J Biol Chem 278:29174-29183.

Jan LY, Jan YN (1997) Cloned potassium channels from eukaryotes and prokaryotes. Annu Rev Neurosci 20:91-123.

Jelacic TM, Kennedy ME, Wickman K, Clapham DE (2000) Functional and biochemical evidence for G-protein-gated inwardly rectifying $\mathrm{K}^{+}$ (GIRK) channels composed of GIRK2 and GIRK3. J Biol Chem 275:36211-36216.

Jiang Y, Lee A, Chen J, Cadene M, Chait BT, MacKinnon R (2002) The open pore conformation of potassium channels. Nature 417:523-526.

Jin T, Peng L, Mirshahi T, Rohacs T, Chan KW, Sanchez R, Logothetis DE (2002) The (beta)gamma subunits of $\mathrm{G}$ proteins gate a $\mathrm{K}^{+}$channel by pivoted bending of a transmembrane segment. Mol Cell 10:469-481.

Jones P, Tucker S, Ashcroft F (2001) Multiple sites of interaction between the intracellular domains of an inwardly rectifying potassium channel, Kir6.2. FEBS Lett 508:85-89.

Karschin C, Dissmann E, Stuehmer W, Karschin A (1996) IRK(1-3) and GIRK(1-4) Inwardly rectifying $\mathrm{K}^{+}$channel mRNAs are differentially expressed in the adult rat brain. J Neurosci 16:3559-3570.

Kennedy ME, Nemec J, Corey S, Wickman K, Clapham DE (1999) GIRK4 confers appropriate processing and cell surface localization to G-proteingated potassium channels. J Biol Chem 274:2571-2582.

Kobayashi T, Ikeda K, Ichikawa T, Abe S, Togashi S, Kumanishi Y (1995) Molecular cloning of a mouse G-protein-activated $\mathrm{K}^{+}$channel (mGIRK1) and distinct distributions of three GIRK (GIRK1, 2 and 3) mRNAs in mouse brain. Biochem Biophys Res Commun 208:1166-1173.
Kofuji P, Davidson N, Lester HA (1995) Evidence that neuronal Gprotein-gated inwardly rectifying $\mathrm{K}^{+}$channels are activated by $\mathrm{G} \beta \gamma$ subunits and function as heteromultimers. Proc Natl Acad Sci USA 92:6542-6546.

Krapivinsky G, Krapivinsky L, Wickman K, Clapham DE (1995a) G $\beta \gamma$ binds directly to the $\mathrm{G}$ protein-gated $\mathrm{K}^{+}$channel, $\mathrm{I}_{\mathrm{KACh}}$. J Biol Chem 270:29059-29062.

Krapivinsky G, Gordon EA, Wickman K, Velimirovic B, Krapivinsky L, Clapman DE (1995b) The G-protein-gated atrial $\mathrm{K}^{+}$channel $\mathrm{I}_{\mathrm{KACh}}$ is a heteromultimer of two inwardly rectifying $\mathrm{K}^{+}$-channel proteins. Nature 374:135-141.

Krapivinsky G, Kennedy ME, Nemec J, Medina I, Krapivinsky L, Clapham DE (1998) G $\beta \gamma$ binding to GIRK4 subunit is critical for $G$ protein-gated $\mathrm{K}^{+}$ channel activation. J Biol Chem 273:16946-16952.

Kubo Y, Baldwin TJ, Jan YN, Jan LY (1993a) Primary structure and functional expression of a mouse inward rectifier potassium channel. Nature 362:127-133.

Kubo Y, Reuveny E, Slesinger PA, Jan YN, Jan LY (1993b) Primary structure and functional expression of a rat G-protein-coupled muscarinic potassium channel. Nature 364:802-806.

Kuo A, Gulbis JM, Antcliff JF, Rahman T, Lowe ED, Zimmer J, Cuthbertson J, Ashcroft FM, Ezaki T, Doyle DA (2003) Crystal structure of the potassium channel KirBacl.1 in the closed state. Science 300:1922-1926.

Leaney JL (2003) Contribution of Kir3.1, Kir2.3A, and Kir3.2C subunits to native $\mathrm{G}$ protein-gated inwardly rectifying potassium currents in cultured hippocampal neurons. Eur J Neurosci 18:2110-2118.

Lesage F, Duprat F, Fink M, Guillemare E, Coppola T, Lazdunski M, Hugnot J-P (1994) Cloning provides evidence for a family of inward rectifier and G-protein coupled $\mathrm{K}^{+}$channels in the brain. FEBS Lett 353:37-42.

Lesage F, Guillemare E, Fink M, Duprat F, Heurteaux C, Fosset M, Romey G, Barhanin J, Lazdunski M (1995) Molecular properties of neuronal G-protein-activated inwardly rectifying $\mathrm{K}^{+}$channels. J Biol Chem 270:28660-28667.

Lippiat J, Albinson S, Ashcroft F (2002) Interaction of the cytosolic domains of the Kir6.2 subunit of the $\mathrm{K}_{\mathrm{ATP}}$ channel is modulated by sulfonylureas. Diabetes 51:377-380.

Logothetis DE, Kurachi Y, Galper J, Neer EJ, Clapham DE (1987) The $\beta \gamma$ subunits of GTP-binding proteins activate the muscarinic $\mathrm{K}^{+}$channel in heart. Nature 325:321-326.

Lupas A (1996) Coiled coils: new structures and new functions. Trends Biochem Sci 21:375-382.

Lupas A, VanDyke M, Stock J (1991) Predicting coiled coils from protein sequences. Science 252:1162-1164.

Ma D, Jan LY (2002) ER transport signals and trafficking of potassium channels and receptors. Curr Opin Neurobiol 12:287-292.

Ma D, Zerangue N, Raab-Graham K, Fried SR, Jan YN, Jan LY (2002) Diverse trafficking patterns due to multiple traffic motifs in $G$ proteinactivated inwardly rectifying potassium channels from brain and heart. Neuron 33:715-729.

Mirshahi T, Logothetis DE (2004) Molecular determinants responsible for differential cellular distribution of GIRK channels. J Biol Chem 279:11890-11897.

Nishida M, MacKinnon R (2002) Structural basis of inward rectification: cytoplasmic pore of the $\mathrm{G}$ protein-gated inward rectifier GIRK1 at $1.8 \mathrm{~A}$ resolution. Cell 111:957-965.

Philipson LH, Kuznetsov A, Toth PT, Murphy J, Szabo G, Ma GH, Miller RJ (1995) Functional expression of an epitope-tagged G-protein-coupled $\mathrm{K}^{+}$channel (GIRK1). J Biol Chem 270:14604-14610.

Qu Z, Yang Z, Cui N, Zhu G, Liu C, Xu H, Chanchevalap S, Shen W, Wu J, Li Y, Jiang C (2000) Gating of inward rectifier $\mathrm{K}^{+}$channels by protonmediated interaction of $\mathrm{N}$ - and $\mathrm{C}$-terminal domains. J Biol Chem 275:31573-31580.

Reuveny E, Slesinger PA, Inglese J, Morales JM, Iñiguez-Liuhi JA, Lefkowitz RJ, Bourne HR, Jan YN, Jan LY (1994) Activation of the cloned muscarinic potassium channel by $\mathrm{G}$ protein $\beta \gamma$ subunits. Nature 370:143-146.

Riven I, Kalmanzon E, Segev L, Reuveny E (2003) Conformational rearrangements associated with the gating of the $\mathrm{G}$ protein-coupled potassium channel revealed by FRET microscopy. Neuron 38:225-235.

Sadja R, Smadja K, Alagem N, Reuveny E (2001) Coupling Gbetagamma-- 
dependent activation to channel opening via pore elements in inwardly rectifying potassium channels. Neuron 29:669-680.

Schulte U, Hahn H, Wiesinger H, Ruppersberg J, Fakler B (1998) pHdependent gating of ROMK $\left(\mathrm{K}_{\mathrm{ir}} 1.1\right)$ channels involves conformational changes in both N and C termini. J Biol Chem 273:34575-34579.

Sui JL, Petit-Jacques J, Logothetis DE (1998) Activation of the atrial $\mathrm{K}_{\mathrm{ACh}}$ channel by the $\beta \gamma$ subunits of $\mathrm{G}$ proteins or intracellular $\mathrm{Na}^{+}$ions depends on the presence of phosphatidylinositol phosphates. Proc Natl Acad Sci USA 95:1307-1312.

Tsuboi T, Lippiat J, Ashcroft F, Rutter G (2004) ATP-dependent interaction of the cytosolic domains of the inwardly rectifying $\mathrm{K}^{+}$channel Kir6.2 revealed by fluorescence resonance energy transfer. Proc Natl Acad Sci USA 101:76-81.

Tucker S, Ashcroft F (1999) Mapping of the physical interaction between the intracellular domains of an inwardly rectifying potassium channel, Kir6.2. J Biol Chem 274:33393-33397.

Tucker SJ, Pessia M, Adelman JP (1996) Muscarine-gated $\mathrm{K}^{+}$channel: subunit stoichiometry and structural domains essential for $\mathrm{G}$ protein stimulation. Am J Physiol 271:H379-H385.

Wischmeyer E, Doring F, Wischmeyer E, Spauschus A, Thomzig A, Veh R, Karschin A (1997) Subunit interactions in the assembly of neuronal Kir3.0 inwardly rectifying $\mathrm{K}^{+}$channels. Mol Cell Neurosci 9:194-206.

Woodward R, Stevens EB, Murrell-Lagnado RD (1997) Molecular determinants for assembly of G-protein-activated inwardly rectifying $\mathrm{K}^{+}$channels. J Biol Chem 272:10823-10830.

Yoshii K, Kurihara K (1989) Inward rectifier produced by Xenopus oocytes injected with mRNA extracted from carp olfactory epithelium. Synapse 3:234-238. 